
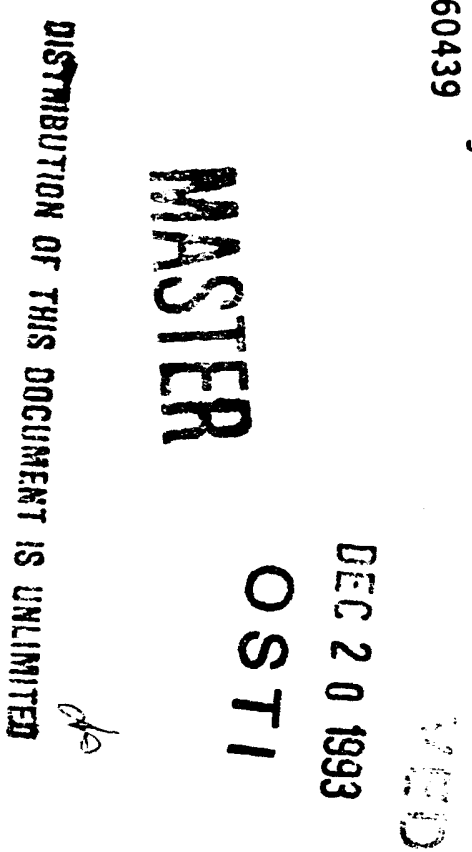

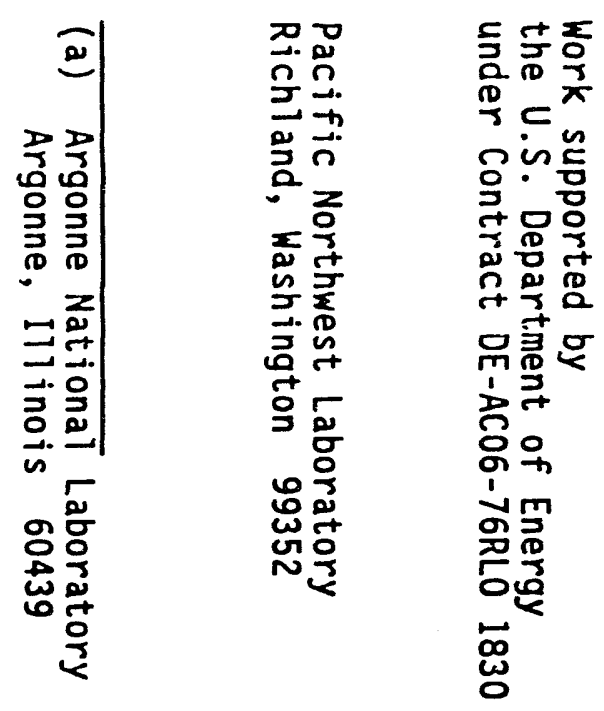
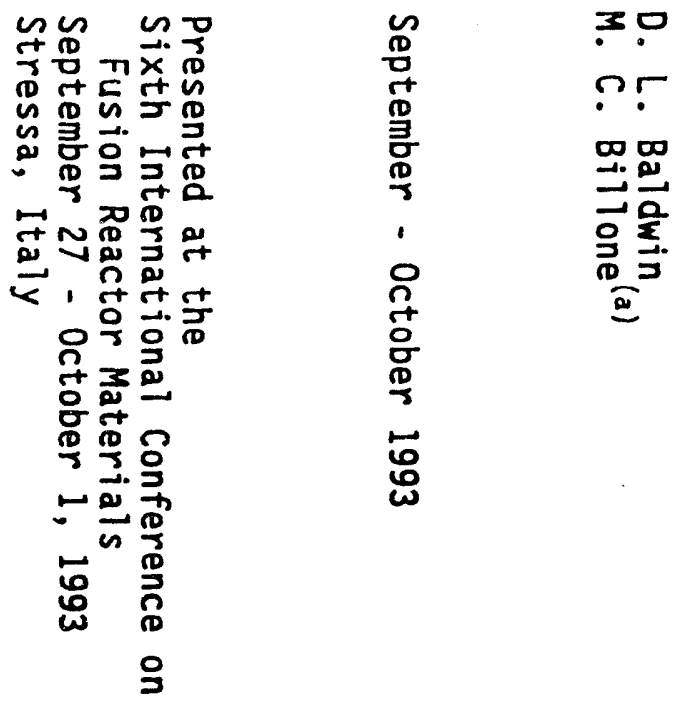

\section{DISCLAIMER}

This report was prepared as an account of work sponsored by an agency of the United States Government. Neither the United States Government nor any agency thereof, nor any of their employees, makes any warranty, express or implied, or assumes any legal liability or responsibility for the accuracy, completeness, or usefulness of any information, apparatus, product, or process disclosed, or represents that its use would not infringe privately owned rights. Reference herein to any specific commercial product, process, or service by trade name, trademark, manufacturer, or otherwise does not necessarily constitute or imply its endorsement, recommendation, or favoring by the United States Government or any agency thereof. The views and opinions of authors expressed herein do not necessarily state or reflect those of the United States Government or any agency thereof.
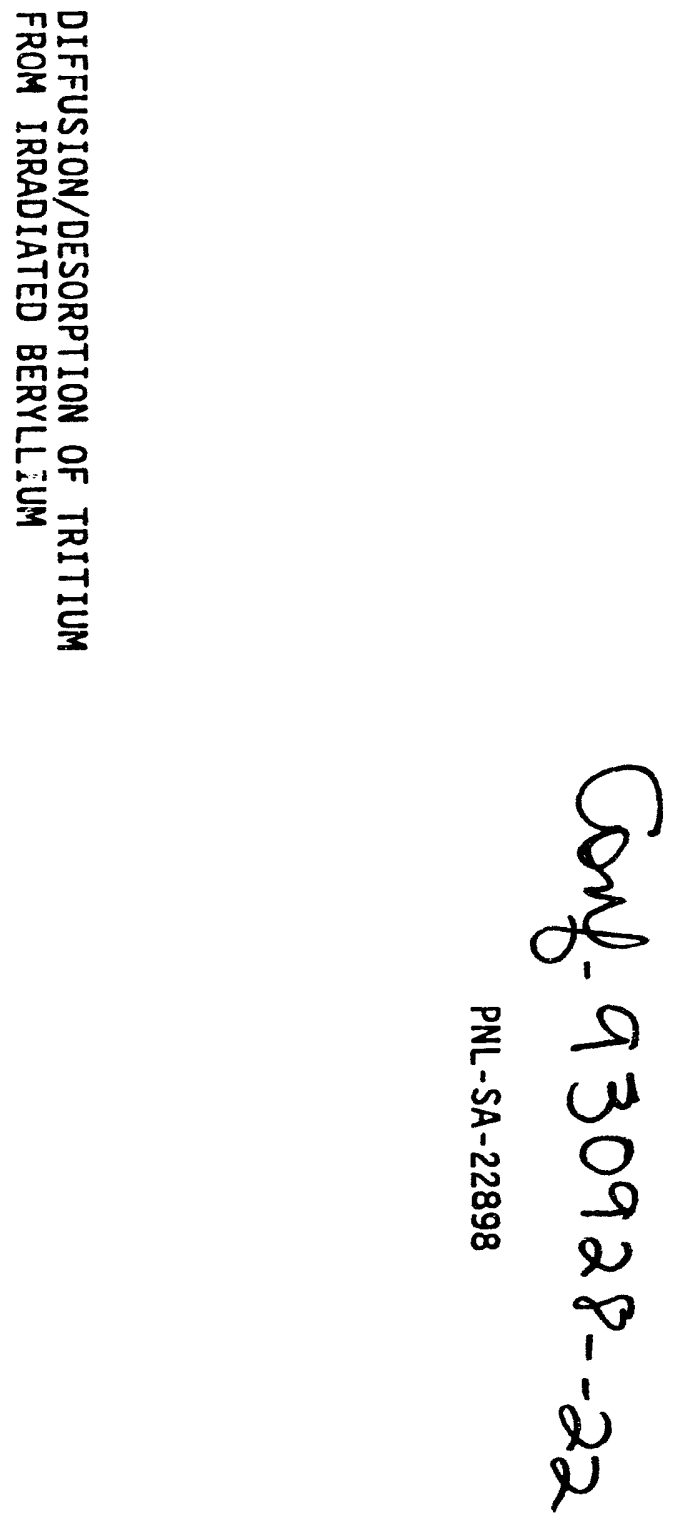


\title{
DIFFUSION/DESORPTION OF TRITIUM FROM IRRADIATED BERYLLIUM
}

\author{
D. L. Baldwin' and M. C. Billone ${ }^{2}$ \\ ${ }^{1}$ Pacific Northwest Laboratory, Richland, WA 99352 \\ ${ }^{2}$ Argonne National Laboratory, Argonne, IL 60439
}

\begin{abstract}
Stepped-thermal-anneal tritium-release measurements at 573 up to $1173 \mathrm{~K}$ have been performed on irradiated Be test materials, fabricated and irradiated to meet conditions relevant to the International Thermonuclear Experimental Reactor (ITER). A combined diffusion/desorption model for tritium release allows determination of diffusion coefficients and desorption-rate constants in the mixed-mechanism regime where both diffusion and surface desorption appear to be rate-limiting. The effective tritium diffusivities $\left(\mathrm{m}^{2} / \mathrm{s}\right)$ for these materials, and al so from new data analys is of previously reported fully dense material, were found to be
\end{abstract}

$$
\begin{aligned}
& 81 \% \text { TD Be: } 1.7 \times 10^{-11} \exp (-3.5 \mathrm{~kJ} / \mathrm{mol} / \mathrm{RT}) \\
& 99 \% \text { TD Be: } 1.6 \times 1.10 \exp (-9.5 \mathrm{~kJ} / \mathrm{mol} / \mathrm{RT}) \\
& 100 \% \text { TD Be: } 1.4 \times 10^{-10} \exp (-11.5 \mathrm{~kJ} / \mathrm{mol} / \mathrm{RT})
\end{aligned}
$$

Tritium release data for both the $81 \%$ TD and the $99 \%$ TD sample were matched reasonab1y wel1 by the diffusion/desorption model. The model provides evidence for a changing mechanism over both temperature and density, but indicates that diffusion is the primary mechanism with a small and changing contribution from surface desorption. 


\title{
DIFFUSION/DESORPTION OF TRITIUM FROM IRRADIATED BERYLLIUM
}

\author{
D. L. Baldwin 1 and M. C. Billone ${ }^{2}$ \\ ${ }^{1}$ Pacific Northwest Laboratory, Richland, WA 99352 \\ ${ }^{2}$ Argonne National Laboratory, Argonne, IL 60439
}

\section{Introduction}

Pacific Northwest Laboratory (PNL) has recently completed ${ }^{3} \mathrm{H}$ and He release studies on two beryllium test materials, which were fabricated and irradiated to meet conditions relevant to the International Thermonuclear Experimental Reactor (ITER). These test samples were fabricated to $81 \%$ and $99 \%$ theoretical density (TD), have moderate $\mathrm{Be} 0$ content, and were irradiated at low temperature to moderate fast-neutron fluence. Stepped thermal anneal tritium release tests, at 573 to $873 \mathrm{~K}$, and in one case up to $1173 \mathrm{~K}$, have been conducted, and the results used to determine ${ }^{3} \mathrm{H}$ diffusion coefficients and desorption-rate constants. Additional data analysis was performed on previously reported release curves, resulting in diffusion coefficients for $100 \%$ TD Be. Tritium and $\mathrm{He}$ assay measurements of the $81 \%$ and $99 \%$ TD materials are reported and presented along with a comparison to similar data for the $100 \%$ TD Be, irradiated to high fast-neutron fluence.

A diffusion/desorption model for ${ }^{3} \mathrm{H}$ release, based on slab geometry, was used to determine diffusion coefficients and surface desorption-rate constants in the mixed-mechanism regime where both mechanisms appear to be rate-limiting. The relative contribution of the two mechanisms is shown to change across the temperature range. The non-diffusional ${ }^{3} \mathrm{H}$ "burst release" observed for all materials at the end of the anneals is also discussed.

\section{Experimental}

Stepped-anneal ${ }^{3} \mathrm{H}$ release testing of both low-density (81\%) and high-density (99\%) Be irradiated in the Advanced Test Reactor (ATR), over $1500 \mathrm{~h}$ periods, was performed. A description of the fabrication and irradiation parameters of these two materials, along with a comparison to the $100 \%$ TD material reported earlier [1,2], is presented in Table 1. Using the experimental apparatus described previously [1], the $81 \%$ TD sample was heated at 573 to $873 \mathrm{~K}$, in isothermal steps of $100 \mathrm{~K}$, with about $400 \mathrm{~h}$ holds at each temperature. The 99\% TD sample was heated in similar fashion from 573 to $973 \mathrm{~K}$, then in $50 \mathrm{~K}$ steps to $1173 \mathrm{~K}$. The hold times for the 973 to $1173 \mathrm{~K}$ range were $24 \mathrm{~h}$ per step to determine the presence and temperature of a burst release. Purge gas $\left(\mathrm{He}-0.1 \% \mathrm{H}_{2}\right)$ at $100 \mathrm{scm}^{3} / \mathrm{min}$ swept the wafer-shaped samples in a quartz system. Important modifications of the previously described

(a) Pacific Northwest Laboratory is operated by Battelle Memorial Institute for the U.S. Department of Energy under Contract DE-ACO676RLO 1830. 


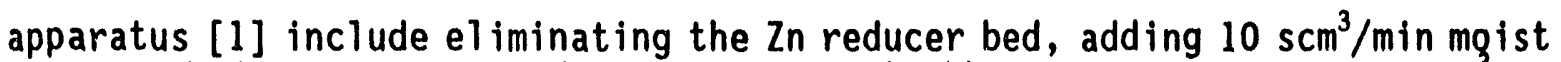
air just before the CuO oxidizer column, and adding a pair of sequential ${ }^{3}$ HTO collection bubblers, replacing the molecular sieve columns.

In the case of the $81 \%$ TD sample, two independent release curves were obtained, generated by integration of the ionization chamber signal and by cumulative collection bubbler/liquid scintillation measurement. Because the 99\% TD sample contained a small quantity of ${ }^{3} \mathrm{H}$, and had a comparatively large ionization chamber background level, the release curve was determined by cumulative collection bubbler/liquid scintillation measurement only. Cumulative collection bubbler data represent a "hard" data set, not requiring interpretation or correction. By comparison, integrated ionization chamber data represent a "soft" data set, requiring difficult time-dependent background-correction and possible correction due to calibration shifts. A dual data-collection scheme achieves a significant increase in the quality of information, allowing better data interpretation. In the first test with $81 \%$ TD $\mathrm{Be}$, the integrated ionization chamber release curve was backgroundcorrected to precisely fit the collection bubbler data set, while the 99\% TD curve is based on collection bubbler results only. The ${ }^{3} \mathrm{H}$ release fractions, $\mathrm{R} \quad\left({ }^{3} \mathrm{H}\right.$ release)/I (initial inventory) versus time, at each of the temperatures, for the $81 \%$ and $99 \%$ TD Be specimens, are shown in Figure 1.

\section{Diffusion/Desorption Mode1}

A combined diffusion/desorption model is used to analyze the present ${ }^{3} \mathrm{H}$ release data. The diffusion part of the model assumes that for a sample with initial ${ }^{3} \mathrm{H}$ inventory, $\mathrm{I}_{0}$, the ${ }^{3} \mathrm{H}$ released after long $t i m e, \mathrm{R}_{\infty}$, at an isothermal annealing temperature is uniformly distributed and available for transport in the bulk at the beginning of the anneal. The characteristic path length for diffusion is the half-width, $\ell$, of the wafer-like samples. The presence of any BeO surface layer is not modeled. Thus the diffusivity determined by matching predictions to data is considered an "effective" diffusivity, $D_{\text {eff }}$. The surface-desorption part of the model assumes first-order kinetics, given the very high $H / T$ ratio due to the protium-rich purge gas. Because the purge flow rate is much faster than the $\mathrm{HT}$ release rate, adsorption of ${ }^{3} \mathrm{H}$ from the purge to the solid and solubility due to gas-solid equilibrium are treated as negligible. As the oxide layer at the surface may change during an anneal, the rate constant for this process is also to be considered an "effective" one, $k_{\text {eff }}$.

The mathematical expression of the diffusion/desorption model, solving for the release fraction, $f_{r}=R_{t} / R_{\infty}$, as function of time, is derived from Carslaw and Jaeger [3] as

$$
f_{r}=1-2 h^{2} \sum_{n=1}^{\infty} \beta_{n}^{-2}\left[\beta_{n}^{2}+h(h+1)\right]^{-1} \exp \left(-\beta_{n}^{2} t / \tau_{1}\right)
$$


where $\beta_{n} \tan \beta_{n}=h=k_{\text {eff }} \ell / D_{\text {eff }}, \tau_{1}=\ell^{2} / D_{\text {eff }}, D_{\text {eff }}=D_{0} \exp \left(-Q_{1} / R T\right)$ in $\mathrm{m}^{2} / \mathrm{s}$, and $k_{\text {eff }}=k^{n} \exp ^{n}\left(-Q_{2} / R T\right)$ in $m / s, t=$ time in $s$, $\ell^{\prime}=$ slab half-thickness in $m, R$ $=8.314 \times 10^{-3} \mathrm{~kJ} / \mathrm{mol}-\mathrm{K}$, and $\mathrm{T}=$ temperature in $\mathrm{K}$.

While no simple way exists to determine $D$ and $k$ from a data set with this equation, it is possible to vary $D$ and $k$ in a constrained manner $(h=k e / D)$ until a best fit is obtained. The $h$-parameter acts as an indicator of ratelimiting mechanism, for as $h \rightarrow \infty$, diffusion becomes limiting, and as $h \rightarrow 0$, desorption becomes limiting. Mathematically, the long-time behavior of the ${ }^{3} \mathrm{H}$ release fraction can be expressed as

$$
1-f_{r}=1-A \exp (-B t)
$$

For diffusion controlled behavior, this implies that:

$$
D \text { in } \mathrm{m}^{2} / \mathrm{s}=\mathrm{B}\left(4 / \pi^{2}\right) e^{2}
$$

For desorption-controlled release, the results imply:

$$
k \text { in } \mathrm{m} / \mathrm{s}=\mathrm{B} \ell
$$

For combined diffusion-desorption controlled behavior, the results imply:

$$
D \text { in } \mathrm{m}^{2} / \mathrm{s}=B \ell^{2} / \beta^{2}
$$

where $\beta_{1} \tan \beta_{1}=h$, and $\beta_{1}$ is the lowest value of $\beta_{n}$.

A regression analysis of the long-time ${ }^{3} \mathrm{H}$ release data gives a value for the slope, B, for each data set. This result is us ${ }^{\circ}$ in Eq. $2 c$ to determine a relationship between $D$ and $h$. A spreadsheet, del is then used to vary $h$ from 0 to infinity in Eq. 1 (with the corrsponding $D$ vs. $h$ constrained by Eq. 2c) until a best-fit of the whole time-history of the experimental $f$ for $a$ given temperature anneal is obtained. The surface desorption-rate constant, $k$, is then determined for each case from $k=D h / l$. This method thus provides, with the graphically determined best $h$-parameter fit, the optimum $D$ and $k$ for the data set at each temperature.

\section{Discussion}

The summarized ${ }^{3} \mathrm{H}$ and $\mathrm{He}$ assay results and thermal-anneal release data collected over similar temperature ranges are listed in Table 2 . The assay results for the 10 density (81\%) and high density $(99 \%)$ Be were expected to be similar for the two densities due to identical neutron fluence. However, the 10 density sample contained $23 \%$ less ${ }^{3} \mathrm{H}$ and $16 \%$ less He than the higher density sample. This difference is probably caused by loss of ${ }^{3} \mathrm{H}$ and $\mathrm{He}$ during irradiation through interconnected porosity of the low density material, even at the low irradiation temperature. This loss of He from the low density material suggests that the He generation rates established for the high density materials are probably more meaningful. Sannen and De Raedt [4] described ${ }^{3} \mathrm{H}$ and He measurements on high-density (99.5\% TD) Be irradiated at low temperature $(313$ to $323 \mathrm{~K}$ ) and at high fast neutron fluence levels (up 
to $\left.4 \times 10^{22} \mathrm{n} / \mathrm{cm}^{2}, E>1 \mathrm{MeV}\right)$, material and conditions nearly identical to the $100 \% \mathrm{TD} B \mathrm{Be}$ shown in Table 2. They reported a He generation rate of 4900 appm $/ 10^{22} \mathrm{n} / \mathrm{cm}^{2}$, very comparable to the $5300 \pm 300$ value for $100 \%$ TD Be in Table 2. The displayed ${ }^{3} \mathrm{H}$ fractional release values can be seen as a matrix of temperature versus density. The trend in release at 573 to $773 \mathrm{~K}$ versus density shows the importance of porosity on ${ }^{3} \mathrm{H}$ retention in $\mathrm{Be}$. At $773 \mathrm{~K}$, the low density $\mathrm{Be}$ displayed $89 \%{ }^{3} \mathrm{H}$ release, over an order of magnitude greater than for the $99 \%$ or the $100 \%$ TD sample.

Applying the diffusion/desorption model to the $81 \%$ and $99 \%$ TD data sets, a changing $h$-parameter, as a function of temperature and density, was observed, implying changing mechanisms with temperature and density. For both densities, the $h$-parameter was found to range from 1 to $>100$ for all temperatures, implying the rate-limiting mechanism ranged from mixed diffusion/desorption $(h=1)$ to primarily diffusion $(h=>100)$. In the highdensity (99\% TD) Be case, with increasing temperature from 573 to $773 \mathrm{~K}$, the $h$-parameter decreased from 10 to 1 , implying primarily diffusion at the lower temperatures and mixed diffusion and desorption at the higher temperature. In the low-density ( $81 \%$ TD) Be case, the reverse was observed, with the $h$ parameter increasing from 10 to $>100$ with increasing temperature, still indicating primarily diffusion with only a small contribution from desorption.

The resulting effective diffusivities, $D_{\text {eff }}$, are shown in Table 3 , along with the effective desorption-rate constant, $k_{\text {eff }}$. A trend is seen, in the diffusion activation energy, $Q_{1}$, with Be density, implying increasing temperature sensitivity of the diffusion mechanism to increasing density. The desorption activation energy, $Q_{2}$, ranged from 4.6 to $18 \mathrm{~kJ} / \mathrm{mol}$, extending higher than $Q_{1}$. The diffusion time constant, $\tau$, not to be confused with ${ }^{3} \mathrm{H}$ residence time, ranges from 140 to $1250 \mathrm{~h}$, showing relative insensitivity to Be density.

The results of this analysis indicate that diffusion is the primary ratelimiting mechanism. Thus, the selection of the proper diffusional dimension over this wide density range becomes important. At 100\% TD, slab geometry, with its corresponding half-thickness, $\ell$, was used, based on the metallic character of Be, instead of grain size or some average particle size. Compared with 10 to $40 \mu$ grain size, $2 \ell$ ranges from 3 to $5 \mathrm{~mm}$. As porosity increases from essentially zero to about $20 \%$, a decrease in the modeling dimension could be considered, although it was not done in this work. For all three densities studied, the slab half-thickness was used for the diffusion pathlength for self-consistency, resulting in $D_{e f f}$.

As can be seen from Fig. 2, the $D_{\text {ff }}$ determined from this study are consistent in terms of activation energy with those determined by Jones and Gibson [8], and by Abramov [9] from permeation tests on unirradiated Be. The orders of magnitude are also consistent with each other as well as other data on hydrogen-isotope diffusion in metals. The results of Kawamura [10], however, show an activation energy much higher and more typical of metal oxides (e.g., $\mathrm{Be0}$ ). The magnitude is also much lower than the current study in the temperature range of interest. 
Tritium release from and retention in Be appear to be governed by more than one mechanism, i.e., either diffusion, surface desorption, or some combination of these two, as well as some trapping mechanism. The residual ${ }^{3} \mathrm{H}$ in the sample after annealing at a particular temperature suggests that ${ }^{3} \mathrm{H}$ is "trapped" either by impurities (e.g., Be0) or by irradiation-induced defects (e.g., He atoms or bubbles). Macauley-Newcombe [5] and Swansiger [6] describe the importance of the Be0 layer in any permeation or diffusion measurement of Be. During post-irradiation annealing, there may be a time dependence to the detrapping of ${ }^{3} \mathrm{H}$ before it is availabale for diffusion through the bulk and desorption from the surface. Aside from the probable time dependence of detrapping, other parameters that may change during an anneal are He distribution (e.g., atoms changing to individual bubbles changing to interlinked bubbles) and thickness of internal and surface BeO layers. More work needs to be done in these areas to quantify these mechanisms and effects.

The nondiffusional ${ }^{3} \mathrm{H}$ burst release, first predicted [7] in 1985 to occur at about $923 \mathrm{~K}$ due to the migration of He bubbles to form interconnected grainedge tunnels to the surface, has been observed in all these materials, and was first described in [1]. Accumulated evidence includes 1) release-peak widths, 2) nearly complete loss of remaining ${ }^{3} \mathrm{H}$ inventory, 3) before and after SEM photographs showing extensive restructuring and void creation, and 4) time lag of release burst. The observed burst release temperature ( 873 to $1173 \mathrm{~K})$ and observed time $1 \mathrm{lag}(2$ to $4 \mathrm{~h}$ ) appear to be sensitive to density, He content, and irradiation temperature. In contrast to the $873 \mathrm{~K}$ burst releases seen for the 10W-He content $81 \%$ TD and high-He content $100 \%$ TD Be, the 10w-He content $99 \%$ TD Be showed only $10 \%$ of the ${ }^{3} \mathrm{H}$ inventory had been released by $873 \mathrm{~K}$. In this case, the temperature was increased unt il a ${ }^{3} \mathrm{H}$ burst release occurred at $1173 \mathrm{~K}$, releasing the remaining inventory of over $50 \%$ of the total. Surprisingly, the residual He after the burst release from the $81 \%$ TD material was measured at $91 \%$ of original inventory. This high residual level of He apparently indicates that al though the ${ }^{3} \mathrm{H}$ burst release may be caused by He bubble coalescence and void expansion, very little He actually escaped.

\section{Conclusions}

Triiium release measurements and data analysis on three densities of lowirradiation temperature Be have been completed and compared. A clear trend of increased ${ }^{3} \mathrm{H}$ release with lower density is seen. After long-time at 773 $K$, the low-density Be released $89 \%$ of the ${ }^{3} \mathrm{H}$ inventory, while the higher density Be materials released only 0.6 to $3.3 \%$. The He generation rate for this Be was found to range from 3350 to $5300 \mathrm{appm} / 10^{22} \mathrm{n} / \mathrm{cm}^{2}$.

The effective ${ }^{3} \mathrm{H}$ diffusivities for the Be materials studied in the present work, and also from new data analys is of the earlier described fully dense material, were found to be

$$
\begin{array}{ll}
81 \% \text { TD Be: } & 1.7 \times 10^{-11} \exp (-3.5 \mathrm{~kJ} / \mathrm{mol} / \mathrm{RT}) \\
99 \% \text { TD Be: } & 1.6 \times 10^{-10} \exp (-9.5 \mathrm{~kJ} / \mathrm{mol} / \mathrm{RT})
\end{array}
$$


$100 \%$ TD Be: $\quad 1.4 \times 10^{-10} \exp (-11.5 \mathrm{~kJ} / \mathrm{mol} / \mathrm{RT})$

Tritium release data for both the $81 \%$ TD and the $99 \%$ TD sample were matched reasonably well by the diffusion/desorption model. The model provides evidence for a changing mechanism over both temperature and density, but indicates that diffusion is the primary mechanism with a small and changing contribution from surface desorption. Future work will focus on the mechanism of ${ }^{3} \mathrm{H}$ trapping in $\mathrm{Be}$ and the time dependence of detrapping as a function of temperature.

\section{Acknowledgements}

The authors wish to acknowledge the laboratory assistance of S. J. Bos, Dr. M. W. Goheen, R. E. Brinson, J. H. Ennen, F. V. Hoopes, and Dr. D. S. Gelles, and the management support of $M$. W. Urie and $A$. G. King.

\section{References}

1. Baldwin, D. L., 0. D. Slagle, and D. S. Gelles, "Tritium Release from Irradiated Beryllium at Elevated Temperatures" J. Nucl. Mat1. 179\&181 (1991) 329-334.

2. Billone, M. C., C. C. Lin, and D. L. Baldwin, "Tritium and Helium Behavior in Irradiated Beryllium", Proceedings of the Ninth Topical Meeting on Fusion Technology, Oakbrook, IL, October 1990.

3. Carslaw, H. S. and J. C. Jaeger, "Conduction of Heat in Solids", University Press, 0xford, 1959.

4. Sannen, L., and Ch. De Raedt, "The Effects of Neutron Irradiation on Beryllium", Proceedings of the 17th Symposium on Fusion Technology, Rome, Italy, September 14-18, 1992.

5. Macauley-Newcombe, R. G., D. A. Thompson, and W. W. Smeltzer, "Thermal Absorption and Desorption of Deuterium in Beryllium and Beryllium Oxide", J. Nucl. Mat1., Vols. 191-194, 263-267.

6. Swansiger, W.A., J. Vac. Sci. Tech., A, 1986, 1216.

7. Baker, C. C., J. N. Brooks, D. A. Ehst, D. L. Smith, and D. K. Sze, "Tokamak Power Systems Studies - FY 1985", ANL/FPP/85-2, 4-304.

8. Jones, P.M.S. and R. Gibson, J. Nucl. Mat1., 21 (1967) 353.

9. Abramov, E., M. P. Riehm, D. A. Thompson, and W. W. Smeltzer, "Deuterium Permeation and Diffusion in High Purity Beryllium", CFFTP-G9013, May 1990. 
10. Kawamura, H., "Retention of Deuterium Implanted in Hot-Pressed Beryllium", J. Nucl. Mat1., $176 \& 177$ (1990) 661-665.

11. Baldwin, D. L. and G. W. Hollenberg, "Measurements of Tritium and Helium in Fast Neutron Irradiated Lithium Ceramics using High Temperature Vacuum Extraction", J. Nucl. Mat1., 141-143, 1986, 305-310 
Table 1: Fabrication and Irradiation Farameters

\begin{tabular}{||l|l|l|l||}
\hline Parameter & $81 \%$ TD & $99 \%$ TD & $100 \%$ TD \\
\hline Fabrication Method & $\begin{array}{l}\text { CIP then } \\
1323 \mathrm{~K}-4 \mathrm{~h}\end{array}$ & $\begin{array}{l}\text { CIP then } \\
1523 \mathrm{~K}-4 \mathrm{~h}\end{array}$ & $\begin{array}{l}\text { HIP unti1 } \\
\text { fully dense }\end{array}$ \\
\hline $\begin{array}{l}\text { Neutron Fluence } \\
\left(\mathrm{n} / \mathrm{cm}^{2},>1 \mathrm{MeV}\right)\end{array}$ & $\begin{array}{l}2.6 \times 10^{21} \\
\left( \pm 0.2 \times 10^{21}\right)\end{array}$ & $\begin{array}{l}2.6 \times 10^{21} \\
\left( \pm 0.2 \times 10^{21}\right)\end{array}$ & $\begin{array}{l}5.0 \times 10^{22} \\
\left( \pm 0.3 \times 10^{22}\right)\end{array}$ \\
\hline Irradiation Temp. & $\approx 348 \mathrm{~K}$ & $\approx 348 \mathrm{~K}$ & $\approx 348 \mathrm{~K}$ \\
\hline Target Density & $80 \% \mathrm{TD}$ & $97 \% \mathrm{TD}$ & $100 \% \mathrm{TD}$ \\
\hline Measured Density & $80.9 \%$ & $99.6 \%$ & $100 \%$ \\
\hline Be0 & $0.9 \mathrm{wt} \%$ & $0.9 \mathrm{wt} \%$ & $1.7 \mathrm{wt} \%$ \\
\hline Grain size & $25 \mathrm{u}$ & $25 \mathrm{u}$ & $10-40 \mathrm{u}$ \\
\hline Estimated swelling & $0.1 \%$ & $0.1 \%$ & $2-3 \%$ \\
\hline
\end{tabular}

Notes:

(1) Fabrication Methods:

81\% TD: Cold isostatically pressed, then sintered at $1323 \mathrm{~K}$ for $4 \mathrm{~h}$. 99\% TD: Cold isostatically pressed, then sintered at $1523 \mathrm{~K}$ for $4 \mathrm{~h}$. 100\% TD: Hot isostatically pressed to full density.

(2) Densities of $80.9 \%$ and $99.6 \%$ TD samples were determined at Rocky Flats after fabrication by dimension and weight measurements. 
Table 2: Tritium and Helium Assay and Release Characteristics

\begin{tabular}{|c|c|c|c|c|}
\hline \multicolumn{2}{|l|}{ Parameter } & $81 \%$ TD & $99 \%$ TD & $100 \%$ TD \\
\hline \multirow{2}{*}{\multicolumn{2}{|c|}{${ }^{3} \mathrm{H}$ Assay (pre-anneal) }} & $6600 \mathrm{MBq} / \mathrm{g}$ & $8570 \mathrm{MBg} / \mathrm{g}$ & $302000 \mathrm{MBg} / \mathrm{g}$ \\
\hline & & $55.3 \mathrm{appm}$ & $71.8 \mathrm{appm}$ & 2530 appm \\
\hline \multirow{2}{*}{\multicolumn{2}{|c|}{${ }^{4}$ He Assay (pre-anneal) }} & $1.82 \mathrm{~cm}^{3} \mathrm{STP} / \mathrm{g}$ & $2.17 \mathrm{~cm}^{3} \mathrm{STP} / \mathrm{g}$ & $65.0 \mathrm{~cm}^{3} \mathrm{STP} / \mathrm{g}$ \\
\hline & & 733 appm & 872 appm & $26100 \mathrm{appm}^{(3)}$ \\
\hline \multicolumn{2}{|c|}{$\begin{array}{l}\text { He Generation Rate } \\
\left(\text { appm } / 10^{22} \mathrm{n} / \mathrm{cm}^{2}\right)\end{array}$} & 2820 & 3350 & $5300 \pm 300$ \\
\hline \multirow{7}{*}{$\begin{array}{l}{ }^{3} \mathrm{H} \text { Fractional } \\
\text { Release (\%) at } \\
\text { Temperature: }\end{array}$} & $573 K^{(2)}$ & 3.2 & 0.10 & 0.01 \\
\hline & $673 \mathrm{~K}$ & 38 & 0.55 & 0.25 \\
\hline & $773 \mathrm{~K}$ & 89 & 3.3 & 0.6 \\
\hline & $873 \mathrm{~K}$ & $99^{(4)}$ & 9.7 & $90^{(4)}$ \\
\hline & $973 \mathrm{~K}$ & $(1)$ & 26.4 & (1) \\
\hline & $1073 \mathrm{~K}$ & (1) & 33.2 & (1) \\
\hline & $1173 \mathrm{~K}$ & (1) & $96.5^{(4)}$ & (1) \\
\hline \multicolumn{2}{|c|}{${ }^{3} \mathrm{H}$ Retention (post-anneal) } & $1.4 \%$ & (1) & $10 \%$ \\
\hline \multicolumn{2}{|c|}{ He Retention (post-anneal) } & $91.7 \%$ & (1) & (1) \\
\hline \multicolumn{2}{|l|}{ Sample Weight } & $0.353 \mathrm{~g}$ & $0.112 \mathrm{~g}$ & $0.473 \mathrm{~g}$ \\
\hline \multicolumn{2}{|c|}{ Sample Thickness } & $5.25 \mathrm{~mm}$ & $4.50 \mathrm{~mm}$ & $3.2 \mathrm{~mm}$ \\
\hline \multicolumn{2}{|c|}{${ }^{3} \mathrm{H}$ Content in Sample } & $2330 \mathrm{MBq}$ & $960 \mathrm{MBq}$ & $143000 \mathrm{MBq}$ \\
\hline
\end{tabular}

Notes:

(1) not measured.

(2) Actual release temperatures of $100 \%$ TD test: $573,684,784,884 \mathrm{~K}$.

(3) The value of $26100 \mathrm{appm}$ He for the $100 \%$ TD Be is a revised value from earlier published data [1] and based on new measurements. This revised value is due to improvements in the analytical method for measuring retained He [11].

(4) Burst release of ${ }^{H}$ observed. 
Table 3: Summary of Tritium Diffusivity and Desorption Rate Constant

\begin{tabular}{|c|c|c|c|}
\hline $\begin{array}{l}\text { Be } \\
\text { Density }\end{array}$ & Time Regime & Diffusivity, $D_{\text {eff }}\left(\mathrm{m}^{2} / \mathrm{s}\right)$ & $\begin{array}{l}\text { Surface Desorption } \\
\text { Rate Constant, keff } \\
(\mathrm{m} / \mathrm{s})\end{array}$ \\
\hline $81 \%$ TD & $50<t<150 h$ & $\begin{array}{l}1.7 \times 10^{-11} \exp (-3.5 \\
\mathrm{kJ} / \mathrm{mol} / \mathrm{RT})\end{array}$ & $\begin{array}{l}8.8 \times 10^{-5} \exp (-18 \\
\mathrm{kJ} / \mathrm{mol} / \mathrm{RT})\end{array}$ \\
\hline $99 \%$ TD & $25<t<400 h$ & $\begin{array}{l}1.6 \times 10^{-10} \exp (-9.5 \pm 3.0 \\
\mathrm{kJ} / \mathrm{mol} / \mathrm{RT})\end{array}$ & $\begin{array}{l}4.8 \times 10^{-8} \exp (-4.6 \\
\mathrm{kJ} / \mathrm{mol} / \mathrm{RT})\end{array}$ \\
\hline $100 \%$ TD & $1<t<25 h$ & $\begin{array}{l}1.4 \times 10^{-10} \exp (-11.5 \\
\mathrm{kJ} / \mathrm{mol} / \mathrm{RT})\end{array}$ & \\
\hline
\end{tabular}




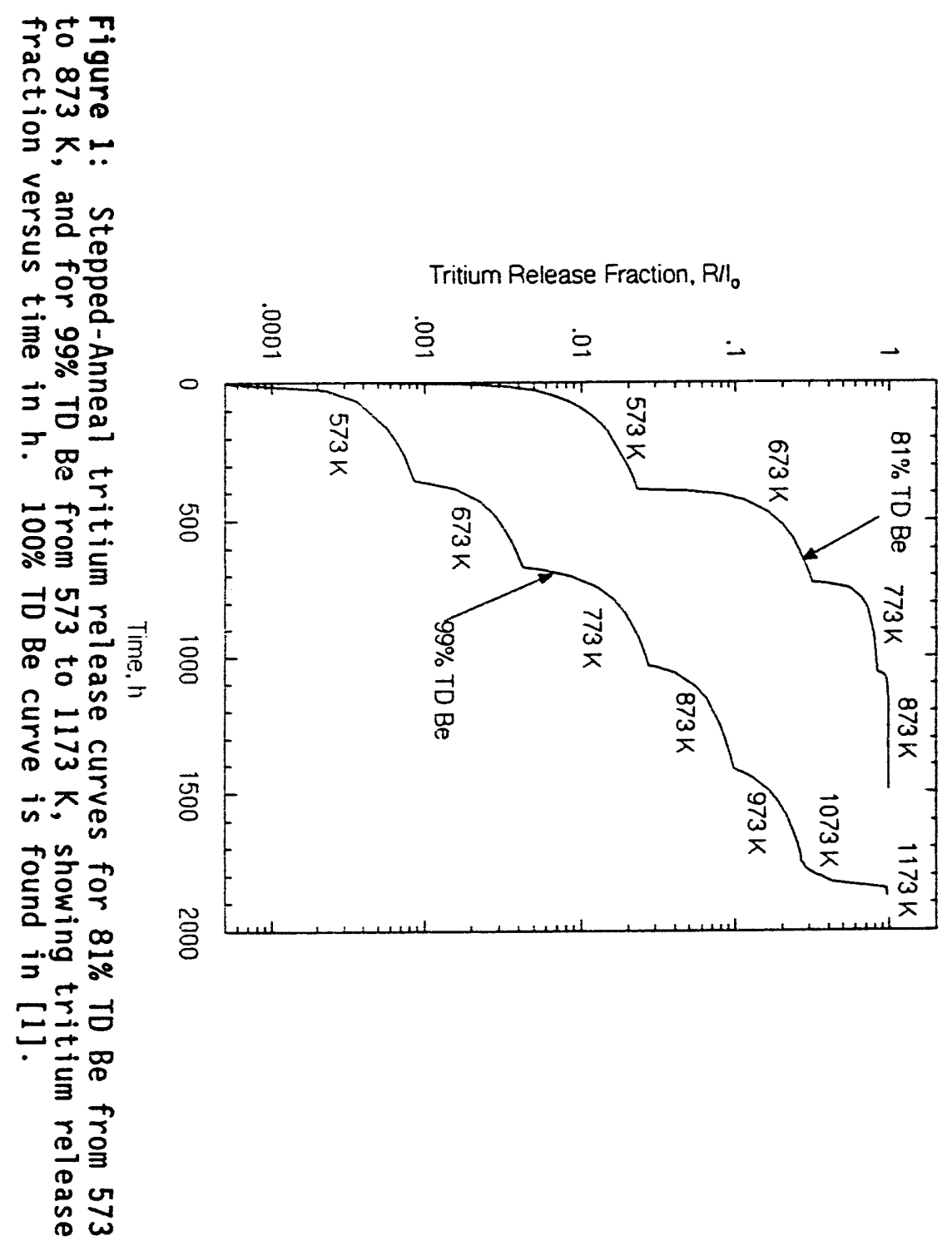




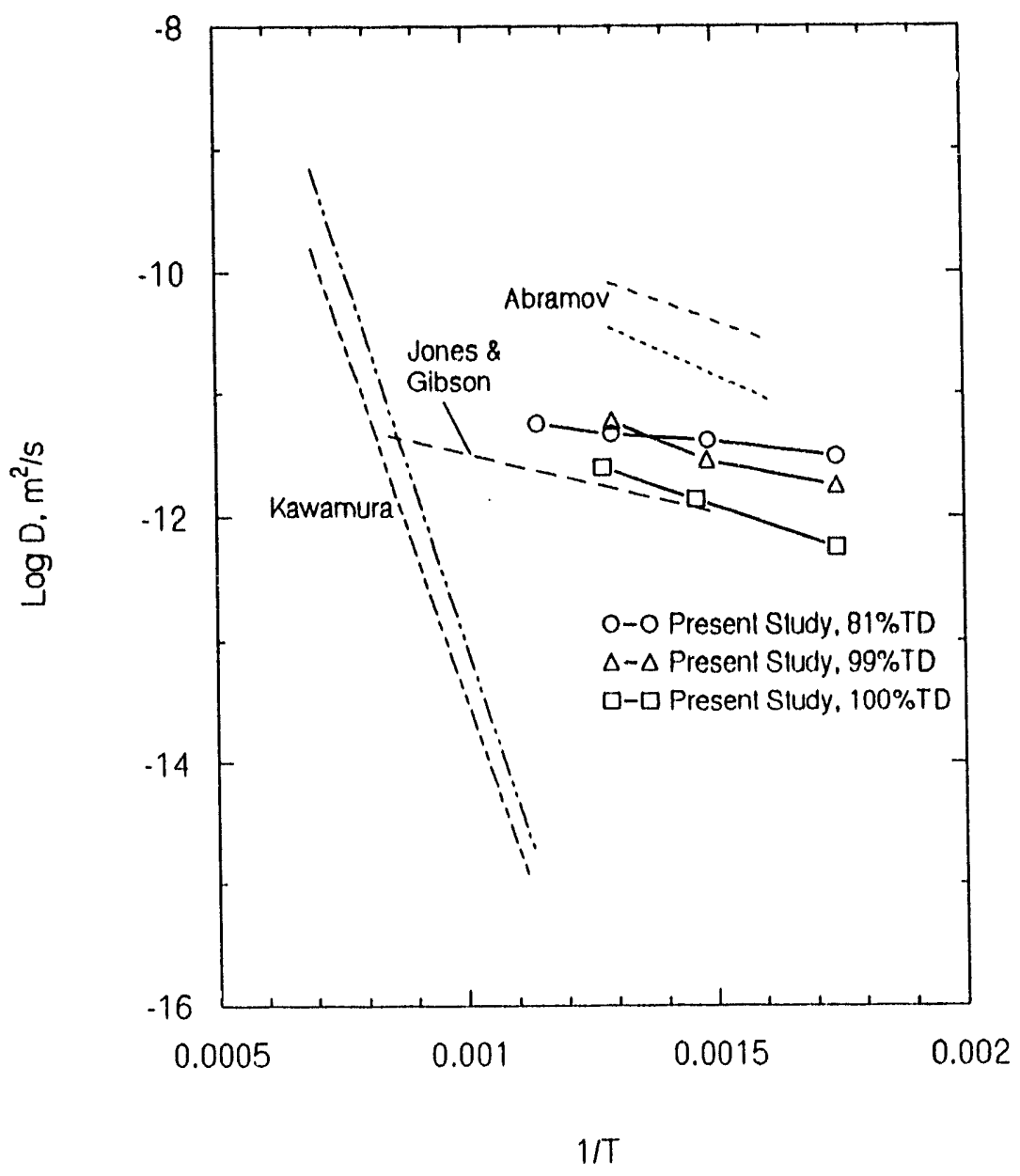

Figure 2: Tritium diffusion coefficients for Be from the present study and from the literature. 

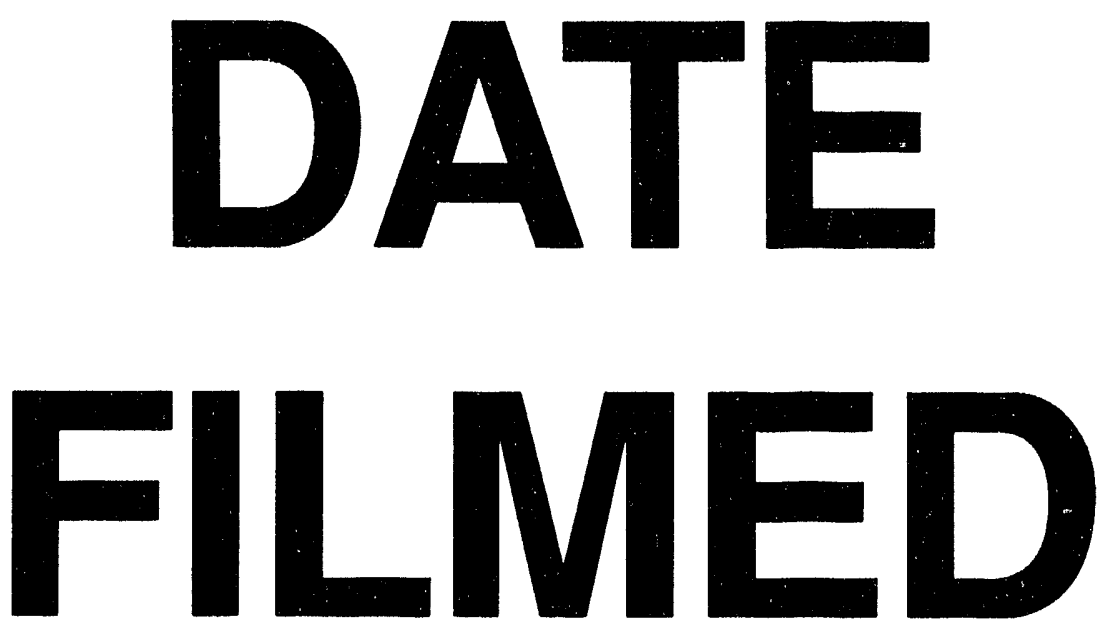

$6 / 2 / 94$
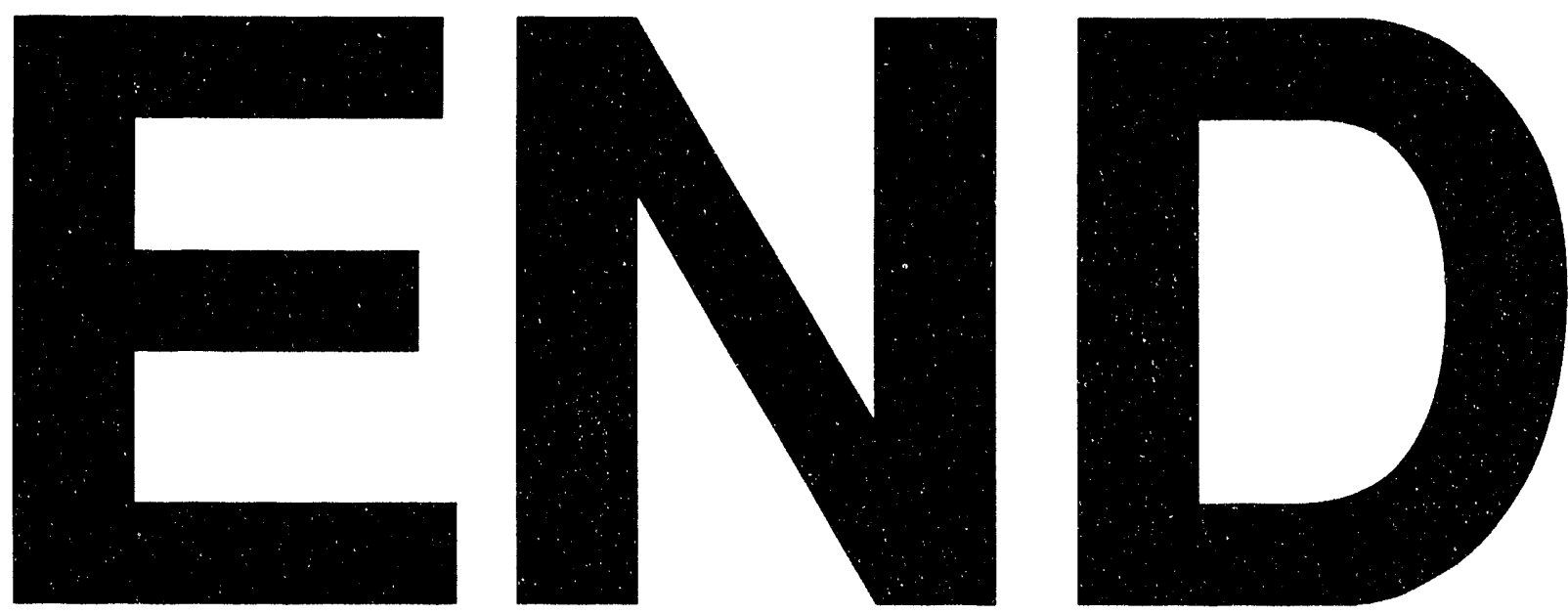
